\title{
Self-similar long profiles of aggrading submarine leveed channels: Analytical solution and its application to the Amazon channel
}

\author{
Benoit Spinewine, ${ }^{1}$ Tao Sun, ${ }^{2}$ Nathalie Babonneau, ${ }^{3}$ and Gary Parker ${ }^{4,5}$ \\ Received 29 November 2010; revised 1 April 2011; accepted 19 April 2011; published 28 July 2011.
}

[1] Many submarine fans are coursed by well-defined leveed channels constructed by turbidity currents. The channels aggrade in time, typically accumulating sandy deposits in their beds and muddy deposits in their levees. Periodic channel avulsion acts to build up the fan as a whole. Here a first theory for the long profile of leveed channels is offered. The theory is based on the assumption that there exists a time period, well after channel initiation but before incipient avulsion, during which the channel and its levees are in a quasi-equilibrium state, concurrently aggrading and prograding onto the surrounding fan. The currents are assumed to deposit sand on the channel bed and mud on the levees. The formulation uses a steady uniform flow assumption and a sediment transport relation inherited from rivers and yields a partial differential equation for the evolution of the channel starting from any initial condition. For the ideal case of a channel forming on an initially unchannelized sloping fan, the theory predicts self-similar long profiles for the down-channel variation of channel bed slope, bed elevation, and width, as well as flow discharge and sand/mud discharges. The time evolution of the channel then amounts to a simple rescaling of the self-similar profile as it aggrades and progrades down fan. The theory, when tested against data from the Amazon channel of the Amazon Submarine Fan, shows encouraging comparisons. The generality and shortcomings of the model assumptions are discussed based on a comparative study of mud-rich and relatively sand-rich submarine fan systems.

Citation: Spinewine, B., T. Sun, N. Babonneau, and G. Parker (2011), Self-similar long profiles of aggrading submarine leveed channels: Analytical solution and its application to the Amazon channel, J. Geophys. Res., 116, F03004, doi:10.1029/2010JF001937.

\section{Introduction}

[2] The Amazon Submarine Fan is not a featureless fanshaped cone of submarine deposits deriving from the Amazon River. Rather, it is intensely channelized, as shown in Figure 1 [Damuth et al., 1988]. The channels tend to be perched above the surrounding fan surface and have sand-rich beds bounded by high, mud-rich levees (Figure 2) [Damuth and Flood, 1985, Normark et al., 1997]. They also display a meandering planform [Pirmez, 1994; Peakall et al., 2000]. They are evidently sculpted by, and serve as the conduits for, turbidity currents carrying a mixture of sand and mud.

\footnotetext{
${ }^{1}$ Fonds de la Recherche Scientifique and Institute of Mechanics, Materials and Civil Engineering, Université catholique de Louvain, Louvain-la-Neuve, Belgium.

${ }^{2}$ ExxonMobil Exploration Co., Houston, Texas, USA.

${ }^{3}$ Laboratoire de Géosciences Marines, CNRS, Université de Brest, Brest, France.

${ }^{4}$ Department of Civil and Environmental Engineering, University of Illinois Urbana-Champaign, Urbana, Illinois, USA.

${ }^{5}$ Department of Geology, University of Illinois Urbana-Champaign, Urbana, Illinois, USA.

Copyright 2011 by the American Geophysical Union. 0148-0227/11/2010JF001937
}

[3] Any given channel undergoes a cycle of initiation, development and abandonment. Initiation is typically associated with an avulsion from an existing channel. The turbidity currents emanating from the breach initially spread out over relatively undifferentiated topography, and are evidently responsible for emplacing the unconfined high-amplitude reflection packets (HARP units) discussed by Pirmez [1994] and Pirmez and Flood [1995]. With the passage of time, however, the turbidity currents self-channelize, initiating the process of levee building [Imran et al., 1998]. The channels then typically aggrade by emplacing sand-rich channel fills responsible for the high-amplitude reflectors (HAR units) schematized on Figure 2, and mud-rich levee deposits. As they aggrade, the channels also extend farther downdip onto the surrounding fan. The channel and levees eventually become so elevated above the surrounding fan that an avulsion occurs, redirecting turbidity currents toward a topographic low on the fan and completing the cycle. The repeated processes of channel initiation, aggradation and avulsion act to build up the fan as a whole.

[4] This picture is apparently not unique to the Amazon Submarine Fan. Similar leveed, meandering channels have been observed on many large fans in the ocean [Clark and Pickering, 1996], including those of the Indus [Kolla and 


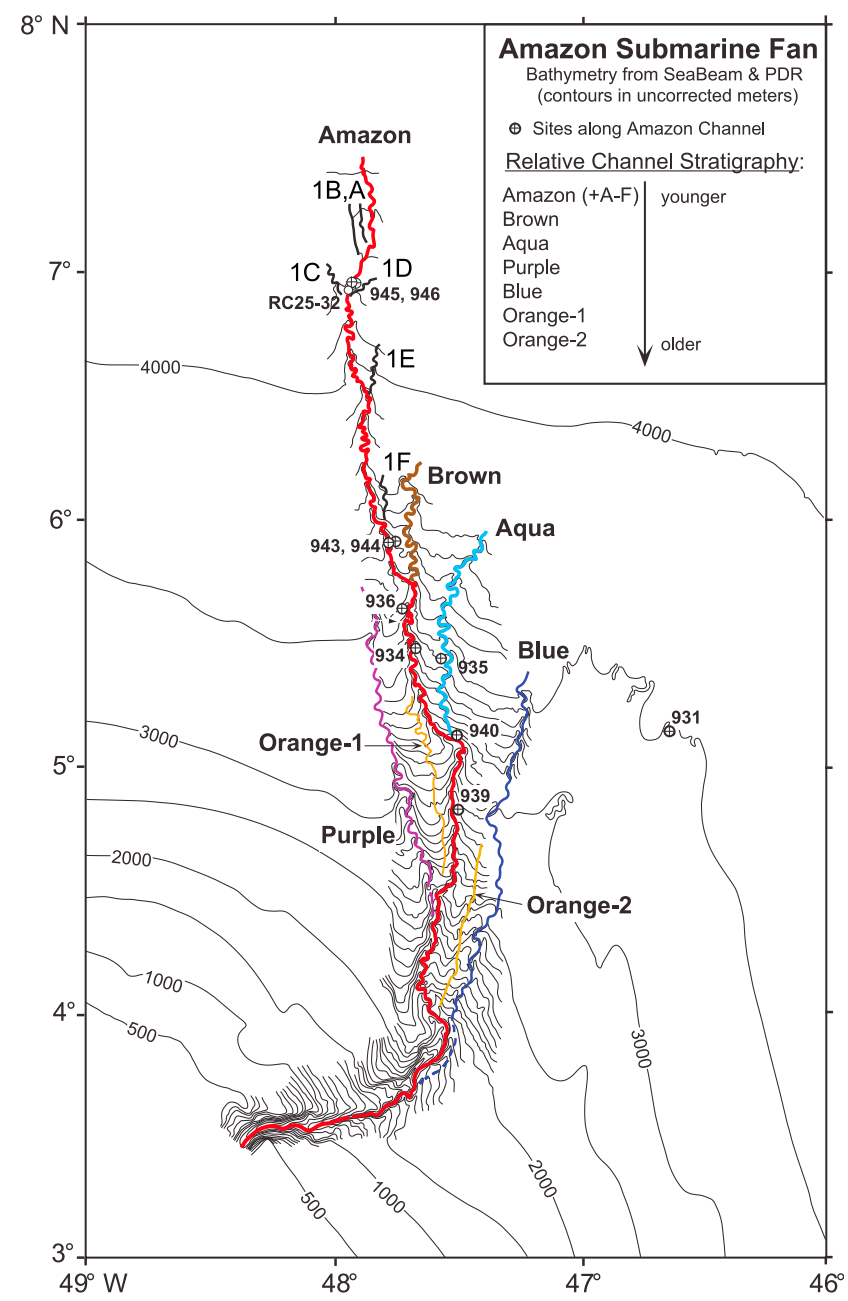

Figure 1. Planform of the Amazon Submarine Fan [from Pirmez and Imran, 2003] (with permission from Elsevier), indicating the latest elongated Amazon channel as well other antecedent paleochannels and ODP core sites.

Coumes, 1987; Kenyon et al., 1995], Mississippi [Twichell et al., 1991] and Zaire [Droz et al., 1996] fans. Common to all of these fans is the observation that they are associated with relatively muddy systems [Reading and Richards, 1994], the mud apparently being necessary for the development of high levees.

[5] The conclusion that both the channels and fans are associated with turbidity currents is not purely inferential, and not limited to very large depositional basins. The formation of a small submarine fan with a leveed, meandering channel was observed in engineering time due to the disposal of waste sediment from the Island Copper Mine, British Columbia, Canada [Hay, 1987a, 1987b]. The waste sediment, which had a broad size distribution ranging from sand to fine silt, was disposed continuously into the ocean as a slurry; the slurry devolved into a turbidity current that was observed using acoustic imaging.

[6] The long profiles of the bed and levees of the Amazon channel, a major channel on the same fan, are shown in Figure 3 [Pirmez, 1994]. Figure 3 contains several features of interest. The channel does not originate on the fan, but instead emanates from a submarine canyon incised into the continental shelf. The profile of the channel bed is concave upward, so displaying the gradual downdip decline in slope that is also characteristic of the long profile of rivers. Finally, through much of its length, i.e., between channel distances of 250 and $600 \mathrm{~km}$ in Figure 3, levee elevation roughly parallels channel bed elevation.

[7] The research reported here represents a first attempt to develop an analytical description of the long profiles of leveed channels on submarine fans. The analysis is based on similar treatments for the long profiles of rivers [e.g., Leopold, 1994; Parker, 1991a, 1991b; Snow and Slingerland, 1987; Sinha and Parker, 1996; Parker and Cui, 1998; Cui and Parker, 1998; Capart et al., 2007] and subaerial fluvial fans [Parker et al., $1998 \mathrm{a}, 1998 \mathrm{~b}$ ] but is specifically adapted to a submarine setting. In the present analysis a quasi-equilibrium state is assumed, according to which the channel/levees aggrade at a rate that is constant in space but declining in time, and prograde at a rate that also declines in time.

[8] The present treatment does not represent the first attempt to parameterize the controls on submarine/subaqueous long profiles. Kneller [2003] discusses the general controls on equilibrium profiles of turbidite slope channels. Lai and Capart [2009] provide a full analytical model of the coevolution of subaerial and subaqueous long profiles associated with hyperpycnal deltas. Gerber et al. [2009] similarly provide an analytical model for the long profile of submarine canyons. Spinewine et al. [2010] propose an analytical solution for the evolution of coarse-grained wedges at the base of canyon slopes and compare the predictions with laboratory experiments. None of these analyses, however, considers the case of quasi-equilibrium coevolution of a long channel and its bounding levees on a submarine fan. In addition, none of these treatments include a salient feature of these channels, i.e., a tendency to narrow in the downstream direction.

\section{Model Assumptions and Governing Equations}

[9] The morphodynamic processes associated with channel development on submarine fans are rather complex. It is postulated here, however, that the long profile of these channels can be adequately explained by means of an abstraction to a smaller number of simpler assumptions concerning flow mechanics and morphology. We anticipate that some assumptions may later be relaxed, or that other combinations of simplified assumptions may lead to different solutions for the channel long-profile development. The assumptions adopted here are enumerated below. They are grounded on observations of submarine channel systems and on parallelisms with similar theories proposed for the long-term evolution of subaerial fluvial channels.

\subsection{Idealized Channel Architecture}

[10] The postulated channel architecture is illustrated in Figure 4. Let $x$ denote down-channel distance and $z$ denote bed elevation. The longitudinal bed slope $S$ is thus given as

$$
S=-\frac{\partial z}{\partial x}
$$

Here it is assumed that this slope represents an average over local variations induced by e.g., bed forms or channel meandering. 


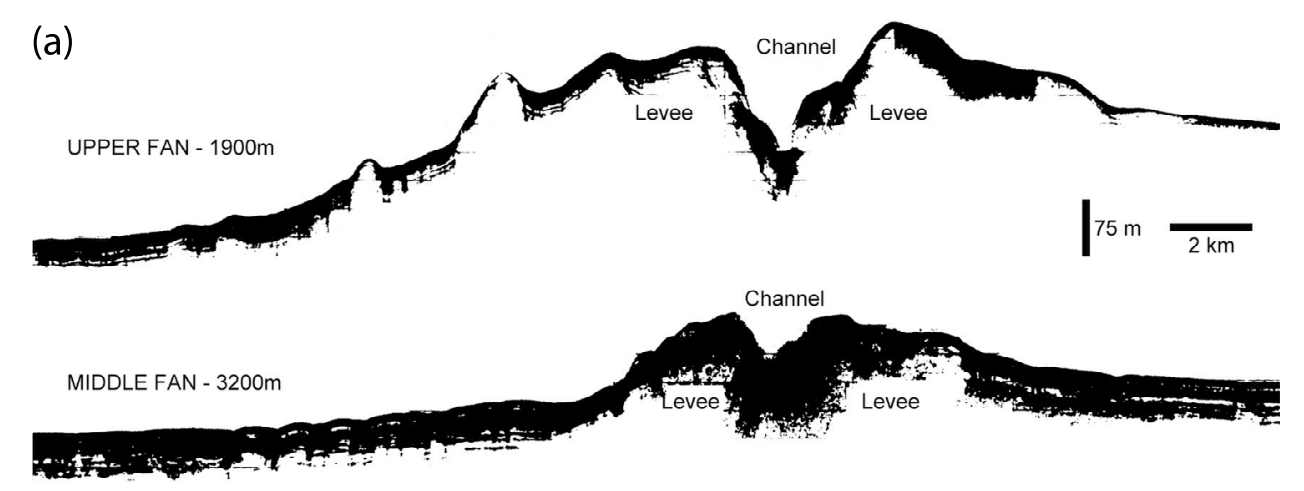

(b)

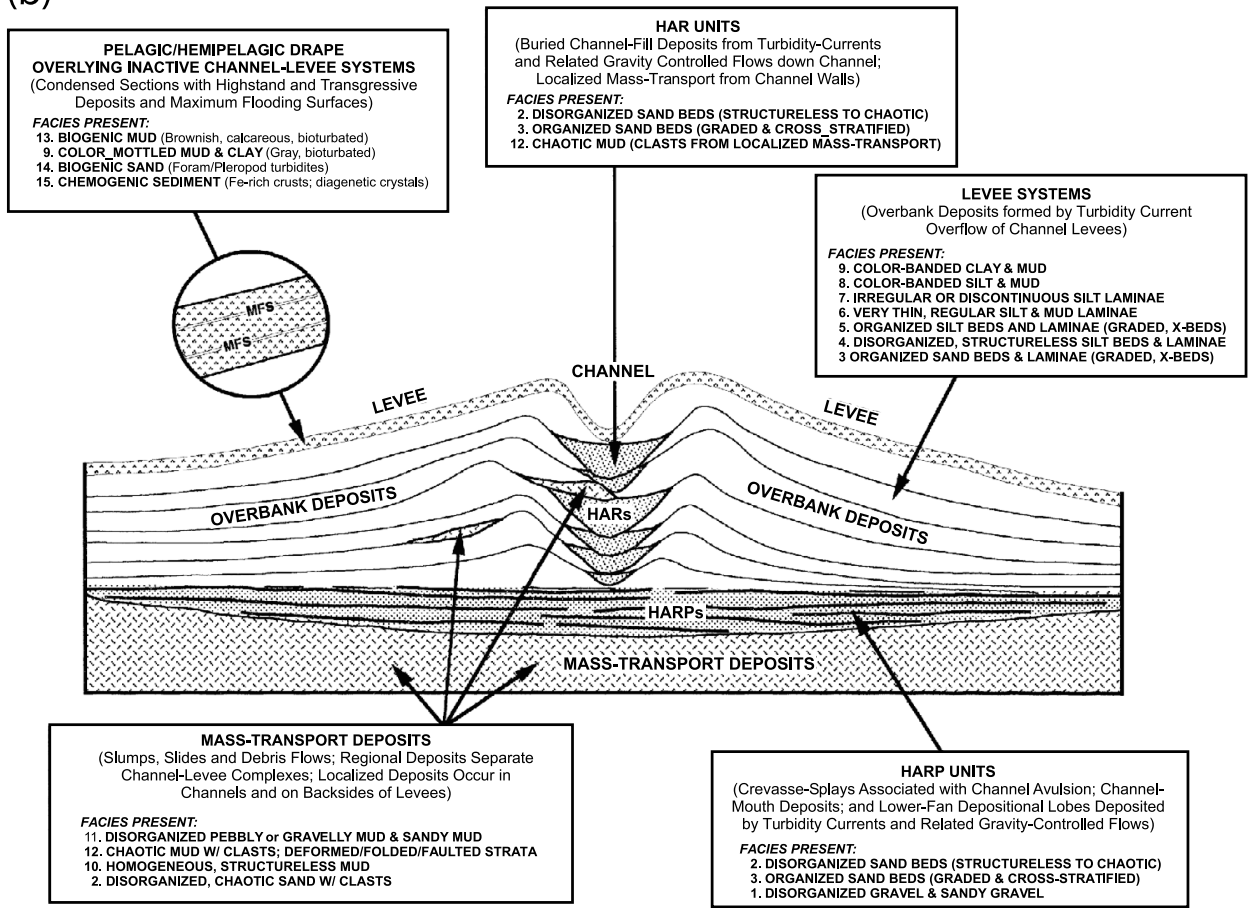

Figure 2. (a) Seismic reflection images of channel cross sections on the Amazon Submarine Fan (redrafted from Damuth and Flood [1985]). Horizontal and vertical bars indicate approximate scale as derived from seismic travel times. (b) Schematized evolution of a leveed channel on the Amazon Submarine Fan, showing the distribution of sedimentary facies within acoustic units (e.g., HAR units, HARP units) and turbidite elements (e.g., channel, levee/overbank, mass transport deposits (MTDs)) of the Amazon Fan. A typical channel-levee system is shown, which is the elemental stratigraphic unit of the fan, and an underlying regional-scale MTD. This stratigraphic relationship is typical of the upper and middle fan [Damuth et al., 1988]. Lower fan deposits lack large channel-levee systems and, for the most part, consist of depositional lobes containing facies comparable to those of the HARP units described in this diagram. From Normark et al. [1997]. MFS, maximum flooding surface.

[11] In the transverse direction, the channel is idealized as having a triangular cross section of width $B$ sandwiched between two triangular levees of width $B_{L} / 2$ on either side. While $B$ may vary downdip as a result of in-channel processes, for simplicity the total width over which the levees develop, $B_{L}$, is assumed to be constant over the entire length of the channel. The deposits below the channel and levee surfaces are approximated as simple prisms. It is assumed that the side slope of the levee represents an average over local variations induced by the presence of sediment waves [Spinewine et al., 2009; Sequeiros et al., 2009; Kostic et al.,
2010], which are commonly found on levees along many channel systems. All together, these assumptions on the channel geometry provide the simplest possible yet realistic abstraction of the leveed channel depicted in Figure 2.

\subsection{Quasi-continuous Turbidity Currents}

[12] The turbidity currents are assumed to be dilute suspensions in the sense that the cross-sectional average volume concentration of suspended sediment does not exceed several percent. This is a typical characteristic for longrunout turbidity currents [Meiburg and Kneller, 2010], and 


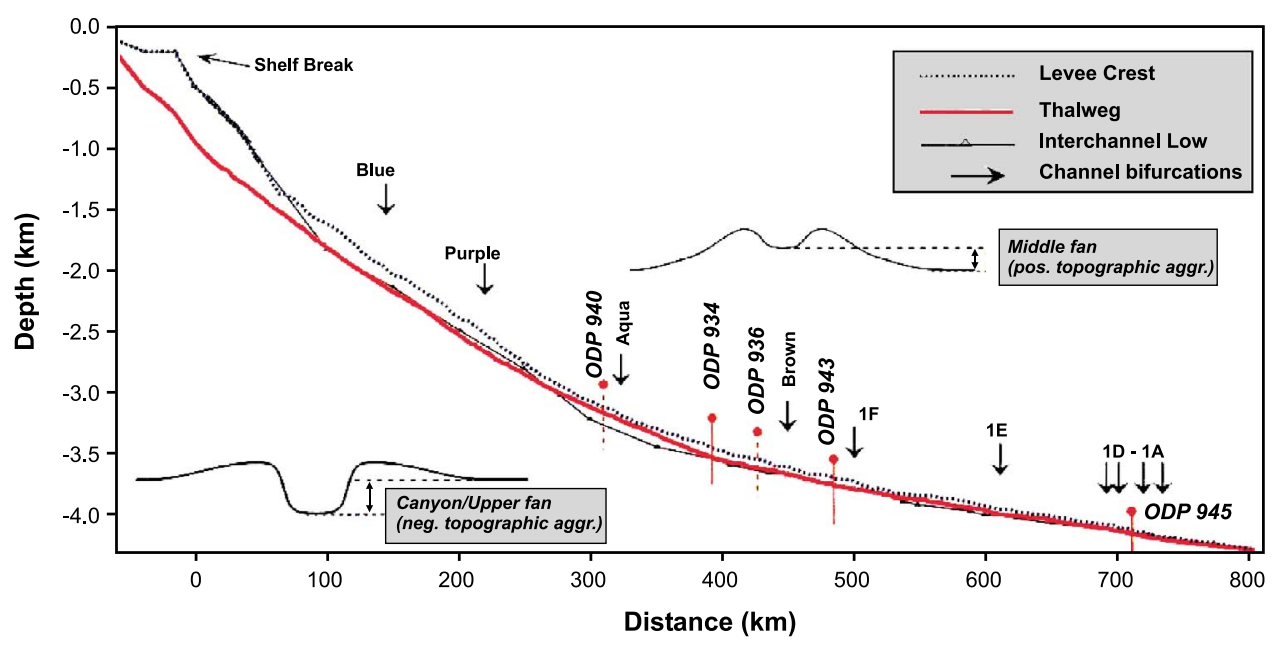

Figure 3. Long profile of the main channel of the Amazon Submarine Fan [from Pirmez and Imran, 2003] (with permission from Elsevier).

one that distinguishes them from other subaqueous sediment-laden flows such as submarine landslides [Masson et al., 2006] and debris flows [Elverhøi et al., 2005]. Average volumetric concentrations of sand and mud $c_{S}$ and $c_{m}$, respectively, can thus be related to the volume flow discharge $Q$, volume sand discharge $Q_{s}$ and volume mud discharge $Q_{m}$ in the following way:

$$
\begin{gathered}
c_{s}=\frac{Q_{s}}{Q+Q_{s}+Q_{m}} \cong \frac{Q_{s}}{Q} \\
c_{m}=\frac{Q_{m}}{Q+Q_{s}+Q_{m}} \cong \frac{Q_{m}}{Q}
\end{gathered}
$$

[13] While, in general, a turbidity current has a definable head, body and tail [Simpson, 1987], the assumption of continuous currents here allows for a description based on quasi-steady flow of the body. The flow events that sculpt the channel are assumed to be quasi-continuous events lasting hours or days [Pirmez and Imran, 2003], so that the morphodynamic evolution of the channel long profile is governed by the quasi-steady flow of the body rather than the short-lasting transient flow of the head or the sedimentstarved diffuse turbid cloud that trails behind the main flow. These flow events punctuate substantially longer periods of inactivity. Here the "flood hydrology" of a turbidity current is abstracted to a current duration $T_{c}$, measured in terms of the time required for the current to completely pass through a given cross section. During this time the current is approximated as steady, so that channel adjustments associated with the current head and tail are neglected. A current event is followed by a duration of inactivity $T_{i}$ between flow events. The intermittency I [Paola, 1989; Paola et al., 1992] is denoted as

$$
I=\frac{T_{c}}{T_{i}+T_{c}}
$$

Here $I$ is taken to be a small number.



Figure 4. Schematization of the assumed simplified architecture of the channel-levee system. (a) Triangular cross section with a sandy channel fill and muddy levees; (b) axonometric view illustrating a downslope reduction in channel width and relief; and (c) channel buildup by concurrent aggradation of the bed and levees. The channel is illustrated as straight only for simplicity. 
[14] The formulation below is developed using a compressed pseudotime $t^{\prime}=t I$ corresponding to a single, continuously maintained current. This current is taken to be characteristic of the range of "channel-forming" currents that are morphologically effective in constructing the leveed channel. Comparisons of predictions with actual time scales for morphological evolution thus require an a posteriori correction to account for the intermittency index.

\subsection{Simplified Flow Mechanics}

[15] Turbidity currents fall in the category of "shallow flows," with the characteristic that their vertical extent (current thickness) is typically one or more orders of magnitude smaller than the horizontal distances over which they develop. As such, the mechanics of turbidity currents may be ascribed to a general set of equations describing layeraveraged momentum and mass balance that are analogous to the St. Venant shallow water equations of river flow [e.g., Parker et al., 1986; Imran et al., 1998]. When describing very long systems, however, momentum balance can be simplified into the equations of "normal flow", i.e., a simple balance between the downdip pull of gravity acting on the flow and the flow resistance. Cui and Parker [1997] have established this result for long rivers; the generalization to turbidity currents is straightforward.

[16] Based on the simplified triangular channel cross section depicted in Figure 4a, the condition of mass conservation of the flow can be written as

$$
Q=\frac{B H}{2} U
$$

where $B$ is the channel width, $H$ is the flow thickness and $U$ is the flow velocity averaged over the cross section. The above condition does not imply that all the current is confined to the channel. Turbidity currents have diffuse interfaces with the ambient water above. It is rather assumed here that the characteristic thickness of the current $H$ (best defined in terms of moments as described by Ellison and Turner [1959], rather than a specific interface) is greater than but loosely tracks channel depth (relief), in that it loses both flow and mud due to overflow. This assumption is reasonable to the extent that a succession of similar turbidity currents created the channel.

[17] For turbidity currents in pseudosteady and uniform conditions, the flow momentum balance reduces to the following normal flow relation, in which the downslope component of gravity on mud and sand is balanced by drag:

$$
R g\left(c_{m}+c_{s}\right) \frac{H}{2} S=C_{f} U^{2}
$$

where $R=\rho_{\mathrm{s}} / \rho_{\mathrm{w}}-1$ is the excess specific density of the sediment relative to the ambient seawater, $g$ is the acceleration of gravity, and $C_{f}$ is a combined dimensionless boundary friction coefficient, assumed constant and accounting for drag acting along the channel bed and along the interface between the current and the ambient. For most natural sediments $\mathrm{R}$ can be expected to have a value near 1.65 .

\subsection{Sediment Transport and Deposition}

[18] The mode of sediment transport is approximated as pure suspension. The sediment of the turbidity current is divided simply into a sand component of a single size and a mud component. The difference in grain size for the two components is responsible for distinct modes of transport. Mud is treated as wash load within the channel and as such does not interact with the channel bed. Sand is transported in suspension but is in equilibrium with the bed.

[19] On one hand, the turbulence of the flow is taken to be sufficient to prevent the deposition of mud on the channel bed. In addition, it is assumed that the mud is well mixed in the vertical up to the interface. For the reasons outlined in section 2.6, the entrainment of ambient water from above is neglected in the present treatment.

[20] The flow is assumed to overflow the channel throughout the domain of interest, and in doing so carry with it the mud from which the bounding levees are constructed. Mud is thus lost to the channel at the same volumetric concentration $c_{m}$ as it is carried in the channel. As a result, the volumetric concentration of suspended mud in the turbidity current can be taken to be constant down the channel:

$$
c_{m}=c_{m 0}
$$

where $c_{m 0}$ is the supplied volumetric concentration of mud in the flow at the entrance of a considered reach. All of the lost mud is assumed to deposit on the levees and build them up. Thus flow discharge $Q$ must decline down the channel at the same fractional rate as mud discharge $Q_{m}$.

[21] On the contrary, sand does interact with the channel bed. It is transported in near-bed suspension at a rate which is essentially a function of the local boundary shear stress. As no specific relation is directly available for the estimation of the suspended sediment transport capacity by turbidity currents in the submarine setting, the rate of sand discharge in the channel is assumed to follow the classical relation for suspended load by Engelund and Hansen [1967], inherited from subaerial flows in sand bed rivers:

$$
Q_{s}=\frac{0.05 B C_{f}^{3 / 2}}{R^{2} g^{2} D} U^{5}
$$

where $D$ is a representative mean diameter of the sand fraction of the sediment.

[22] Being confined in the lower portions of the current, the sand is assumed not to overflow onto the levees and allowed to deposit only on the channel bed. Sediment samples from channel axis (rich sand content) and levees (very small sand content) at ODP wells along the Amazon channel [Flood et al., 1995] tend to substantiate this distinction between $\mathrm{mud} / \mathrm{sand}$ transport modes and deposition patterns.

\subsection{Morphodynamics of Aggradation and Progradation}

[23] Within the lifetime of a submarine channel, the time period of interest to the present study is the intermediate interval well after channel inception but well before incipient avulsion. The fact that the channel levee approximately parallels the channel bed in a central zone of Figure 3 suggests that during this period the bed and levees can be loosely approximated as aggrading concurrently at the same rate. The pattern of consistent channel and levee aggradation is schematized in Figure 4c. 
[24] Aggradation of the channel levee system results from the deposition of a sandy channel ribbon bounded by muddy levees. The rate of aggradation is related to the downchannel reduction in sand and mud discharge, respectively, according to balance relations that express the continuity of sand and mud. Those relations are equivalent to so-called Exner equations known in the field of fluvial morphodynamics. Customized for the present case, they read:

$$
\begin{gathered}
\frac{\partial Q_{s}}{\partial x}=-\left(1-\lambda_{s}\right) B \frac{\partial z}{\partial t^{\prime}} \\
\frac{\partial Q_{m}}{\partial x}=-\left(1-\lambda_{m}\right) B_{L} \frac{\partial z}{\partial t^{\prime}}
\end{gathered}
$$

where $\lambda_{s}$ and $\lambda_{m}$ are typical porosities of the sand and mud deposits, respectively. For now porosities are assumed constant in time and space, and thus one does not consider the reduction of porosities in time as the deposits undergo consolidation.

[25] As the channel and levees are assumed to aggrade at the same rate at any particular location and time, the values of $\partial z / \partial t^{\prime}$ in (8) and (9) are assumed to be identical. The aggradation rate might, however, vary both in time and down the channel. As the channel/levee system extends onto the surrounding fan, the deposits spread over a longer channel reach; as the system aggrades, the bed slope in the proximal zone increases to allow for the transfer of sediments to the more distal reaches. Consequently, one may expect a decreasing aggradation rate in time and down the channel. The assumed pattern of aggradation must fail sufficiently far updip, where the channel emanates from the canyon incised into the shelf. The hypothesis is thus applied only to the aggrading channel system, excluding the canyon upstream. At its downstream end, the aggrading channel extends its length by simultaneously prograding onto the surrounding fan. Indeed, although most of the sand and mud entering the updip end of the reach under consideration is consumed in aggrading the channel over its length, at the far downstream end the remaining sediments suspended in the current are assumed to form the initial deposits that allow the channel system to prograde farther downdip. The vanishing current deposits sandy lobes in the axis of the channel, and mud on the surrounding fan, thus setting the stage for channel extension.

[26] As the channel development matures toward quasiequilibrium conditions, one will see that the proposed theory predicts that the aggradation rate tends toward a constant value in space, though still decreases in time as the channel progressively progrades down fan in a self-similar manner. More specifically, it will be found that the aggradation/ progradation rates decline in time at the rate $t^{-1 / 2}$.

\subsection{Current Self-Containment With Negligible Water Entrainment From Above}

[27] A turbidity current may be either subcritical or supercritical in the sense of the bulk densimetric Froude number $\mathrm{Fr}_{d}$ [Garcia and Parker, 1989]. This dimensionless number expresses the ratio between inertial forces and gravity forces acting on the flow. Specialized to the present currents transporting a mixture of sand and mud in a triangular cross section, it reads

$$
F r_{d}=\frac{U}{\sqrt{R\left(c_{m}+c_{s}\right) g H / 2}}
$$

[28] A supercritical current $\left(F r_{d}>1\right)$ can be expected to continuously entrain ambient sediment-free water from above, so increasing its thickness in the downdip direction. Here the flow is postulated to be subcritical $\left(F r_{d}<1\right)$. Three lines of evidence support this conclusion. The first is the fact that a slope that declines in the downdip direction promotes a transition from Froude supercritical to Froude subcritical flow [Garcia and Parker, 1989]. The second is the inference from Figure 3 that in order to form a channel hundreds of km long, the turbidity current must have been able to track its own channel across the entire length. An ever thickening turbidity current might be expected to eventually become so much thicker than channel depth that it would lose track of the channel. The third line is based on the back calculation of channel formative flows in the Amazon channel of the Amazon Submarine Fan of Pirmez and Imran [2003]. These calculations likewise yield the result of subcritical flow, with $F r_{d}$ taking values well below unity over a $500 \mathrm{~km}$ distal reach over which the channel is perched on the submarine fan.

[29] Note that given the definition of the densimetric Froude number in (10), relation (5) may be rewritten simply as

$$
S=C_{f} F r_{d}^{2}
$$

\subsection{Width Closure}

[30] An additional relation characterizing the downchannel variation of channel width is required to close the problem. The delineation of a physically based relation has proved vexatious even for analyses of the downstream profile of rivers [e.g., Snow and Slingerland, 1987; Sinha and Parker, 1996]. In the case of rivers, bankfull channel width $B$ has been empirically related to bankfull discharge $Q$ to a power which is often found to be close to 0.5 [Leopold, 1994]. Parker et al. [2007] have obtained a partial physical explanation for this behavior. As tributaries enter a river, both $Q$ and $B$ increase downstream.

[31] It is not clear that such a formulation can be directly adapted to the case of channels formed by turbidity currents. As is the case for most levee-bounded channels on submarine fans, the Amazon channel shows a width that decreases monotonically downdip [Pirmez and Imran, 2003]. The sand discharge must also monotonically decrease downdip in a channel undergoing quasi-equilibrium aggradation. In the absence of better information, the following closure relation is used:

$$
B=\gamma Q_{s}^{n}
$$

where $0<n<1$. In principle, the values of $\gamma$ and $n$ are both constant coefficients that must be determined empirically.

[32] The relation $B \sim Q^{0.5}$ for rivers at least has a substantial empirical base. No such base exists for analogous relations for submarine channels. In the absence of appropriate data, then, the exponent $n$ in (12) is used as a fitting 
parameter in combination with the data for the Amazon channel and the present theoretical framework. As noted below, good results were found for the value $n=0.4$.

\section{Channel Morphological Evolution}

[33] It is useful to rewrite the above governing equations in dimensionless form using the following normalizations:

$$
\begin{gathered}
\hat{B}=\frac{B}{B_{0}}, \hat{B}_{L}=\frac{B_{L}}{B_{L 0}}, \hat{Q}=\frac{Q}{Q_{0}}, \hat{S}=\frac{S}{S_{0}}, \hat{Q}_{s}=\frac{Q_{s}}{Q_{s 0}}, \\
\hat{Q}_{m}=\frac{Q_{m}}{Q_{m 0}}, \hat{U}=\frac{U}{U_{0}}, \hat{H}=\frac{H}{H_{0}}
\end{gathered}
$$

where subscripts zeros refer to variable values at the upstream boundary of the considered channel reach (e.g., at the canyon/fan transition).

[34] Note that space coordinates $x$ and $z$ and pseudotime $t^{\prime}$ have not been normalized. A normalization of these variables will be proposed below, based on the assumption of a particular self-similar structure for the morphological evolution of the channel. At this point, however, $x, z$ and $t^{\prime}$ are retained in dimensioned form for generality.

[35] After normalization, the governing equations (1)-(12) can be written as

$$
\begin{gathered}
\hat{S}=-\frac{1}{S_{0}} \frac{\partial z}{\partial x} \\
\hat{Q}=\hat{B} \hat{H} \hat{U} \\
\hat{Q}_{m}=\hat{Q} \\
\hat{Q}_{s}=\hat{B} \hat{U}^{5} \\
\varphi \hat{Q}_{s}+(1-\varphi) \hat{Q}_{m}=\frac{\hat{B} \hat{U}^{3}}{\hat{S}^{\prime}} \\
\frac{\partial \hat{Q}_{s}}{\partial x}=-\alpha \hat{B} \frac{\partial z}{\partial t^{\prime}} \\
\frac{\partial \hat{Q}_{m}}{\partial x}=-\psi \alpha \frac{\partial z}{\partial t^{\prime}} \\
\hat{B}_{L}=1 \\
\hat{B}=\hat{Q}_{s}^{n}
\end{gathered}
$$

where the following parameters have been introduced:

$$
\begin{gathered}
\alpha=\frac{B_{0}\left(1-\lambda_{s}\right)}{Q_{s 0}} \\
\psi=\frac{B_{L}}{B_{0}} r_{p} \frac{\varphi}{1-\varphi} \\
\varphi=\frac{Q_{s 0}}{Q_{s 0}+Q_{m 0}} \\
r_{p}=\frac{1-\lambda_{m}}{1-\lambda_{s}}
\end{gathered}
$$

[36] The postulated mechanism for channel evolution by concurrent aggradation of its sandy bed and muddy levees implies a prescribed relation between the down-fan reduction in sand and mud discharges. Equaling $\partial z / \partial t^{\prime}$ as expressed in (19) and (20), and using (22), one obtains

$$
\frac{\psi}{\hat{Q}_{s}^{n}} \frac{\partial \hat{Q}_{s}}{\partial x}=\frac{\partial \hat{Q}_{m}}{\partial x}
$$

which is easily integrated to obtain the following relation between sand and mud discharges:

$$
\left(\hat{Q}_{m}-1\right)=\frac{\psi}{1-n}\left(\hat{Q}_{s}^{1-n}-1\right)
$$

Using this along with (17) and (22), the normal flow relation (18) and the mass balance relation for sand (19) may be rewritten, after some algebraic developments, as

$$
\begin{gathered}
\frac{1}{\hat{S}}=\frac{1+\varphi r_{p} B_{L} / B_{0}\left(\hat{Q}_{s}^{1-n}-1\right)+\varphi\left(\hat{Q}_{s}-1\right)}{\hat{Q}_{s}^{\frac{3+2 n}{5}}} \\
\frac{\partial \hat{Q}_{s}}{\partial x}=-\alpha \hat{Q}_{s}^{n} \frac{\partial z}{\partial t^{\prime}}
\end{gathered}
$$

These latter two equations form one of the core results of the derivation. In conjunction with (14), they define a system of two coupled partial differential equations in $Q_{s}$ and $z$, which can theoretically be solved for any combination of initial and boundary conditions on these variables. More specifically, (29) and (30) reduce with (14) to a nonlinear diffusion equation of the general form

$$
\frac{\partial z}{\partial t^{\prime}}=f(S) \frac{\partial^{2} z}{\partial x^{2}}
$$

where the function $f(S)$ is determined implicitly from (29) and (30).

[37] However, the nonlinearity in the system (29) and (30) renders it particularly difficult to decouple; while the problem may be solved numerically, a global analytical solution is beyond the scope of the present paper. Fortunately, it turns out that simple solutions may be attained if one assumes that the leveed channel system evolves in a quasi-equilibrium aggrading state, adopting a long profile which is then simply rescaled in space and time in a self-similar way as the channel aggrades and progrades. That is, the governing relations allow self-similar solutions for channel evolution under quasiequilibrium aggrading conditions.

\section{Self-Similar Evolution}

[38] One seeks particular solutions of (29) and (30) that exhibit a self-similar structure. Self-similarity allows relating time and space coordinates in such a way that the time evolution simply amounts to the rescaling of a single profile in a dimensionless system of similarity variables. Selfsimilar analytical solutions for the evolution of long profiles of channels have previously been proposed in the realm of subaerial systems, alluvial rivers and deltas, by various authors [Voller et al., 2004, Capart et al., 2007; Parker et al., 2008]. 


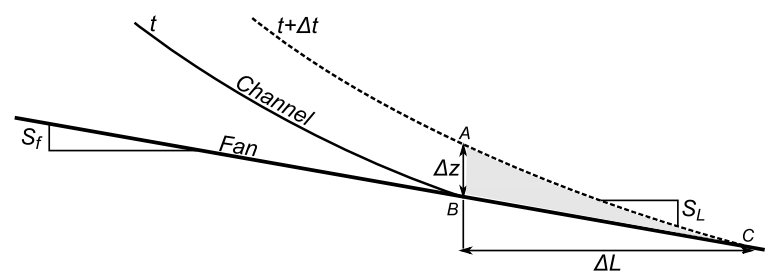

Figure 5. Channel aggradation and subsequent progradation of the channel downstream tip on the surrounding unchanelized fan.

[39] Following the developments of Voller et al. [2004] and Capart et al. [2007], we seek solutions having a selfsimilar structure of the type

$$
z\left(x, t^{\prime}\right)=\hat{z}\left(\frac{x}{L}\right) L\left(t^{\prime}\right)
$$

in which the function $\hat{z}(\hat{x})$ depicts the shape of the self-similar profile in terms of the dimensionless argument $\hat{x}=x / L$, and $L$ is the length over which the profile develops. $L\left(t^{\prime}\right)$ is a function of pseudotime $t^{\prime}$ having the dimensions of length. It captures the rescaling of the self-similar solution as the channel aggrades upward and progrades downstream.

[40] The particular form taken by the function $L\left(t^{\prime}\right)$ may be obtained once appropriate boundary conditions are prescribed at the upstream and downstream end of the channel. First, the similarity structure (32) implies

$$
\frac{\partial z}{\partial x}=\frac{\partial \hat{z}}{\partial \hat{x}}, \frac{\partial^{2} z}{\partial x^{2}}=\frac{1}{L} \frac{\partial^{2} \hat{z}}{\partial \hat{x}^{2}}, \frac{\partial z}{\partial t^{\prime}}=\hat{z} \frac{\partial L}{\partial t^{\prime}}
$$

By plugging these into the system of partial differential equations (29) and (30), one finds $L\left(t^{\prime}\right)$ to be of the form

$$
L\left(t^{\prime}\right)=\sqrt{2 \omega t^{\prime}}
$$

where the scaling constant $\omega$ having dimensions $\mathrm{m}^{2} / \mathrm{s}$ is an effective diffusivity coefficient that depends on imposed boundary conditions and must be determined as part of the solution.

[41] We consider the case of a leveed channel created by turbidity currents exiting from a steep canyon and building up onto an initially unchannelized fan. A fixed slope $S_{0}$ is assumed at the upstream end, where the channel starts to form upon exit from the canyon. Given sand and mud discharges $Q_{s 0}$ and $Q_{m 0}$ are prescribed at that boundary, and updip migration of the canyon/fan transition is disregarded in this first theory. The surrounding fan has a constant slope $S_{F}$.

[42] At its distal end, the channel evolves through simultaneous upward aggradation (at a rate given by $\partial z / \partial t^{\prime}$ ) and down-fan progradation (at a rate given by $\partial L / \partial t^{\prime}$ ). The relative importance of channel aggradation and progradation is not arbitrary, but instead adjusts so that the channel tip maintains a constant slope $S_{L}$, with $S_{L}>S_{F}$, constrained by a shock relation expressing the necessary conservation of bed sediment at the channel tip. This is illustrated in Figure 5, where the bed volume deposited at the channel tip during time interval $\Delta t^{\prime}$ is represented by triangle $\mathrm{ABC}$. Given the constraints on slope $S_{L}$ and $S_{F}$, the following relation must hold:

$$
\left(S_{L}-S_{F}\right)=\frac{\partial z}{\partial t^{\prime}} / \frac{\partial L}{\partial t^{\prime}}
$$

Thus, the difference $\left(S_{L}-S_{F}\right)$ is seen to govern the ratio of relative channel aggradation to progradation.

[43] The assumption of a self-similar structure allows for an analytical solution for the channel evolution. First, the aggradation rate is written in terms of the scaling constant $\omega$ as:

$$
\frac{\partial z}{\partial t^{\prime}}=\left(S_{L}-S_{F}\right) \frac{\partial L}{\partial t^{\prime}}=\frac{\omega\left(S_{L}-S_{F}\right)}{L}
$$

[44] Note that $\omega$ and $\left(S_{L}-S_{F}\right)$ being constants, $\partial z / \partial t^{\prime}$ depends solely on $L$, which by virtue of (34) is a function of pseudotime $\partial t^{\prime}$ only. The aggradation rate is thus constant at each instant over the entire length of the channel, but declines as a function of time to the power $-1 / 2$.

[45] Using (22), (20) is then rewritten in terms of the similarity variable $\hat{x}$ as:

$$
\frac{\partial \hat{Q}}{\partial \hat{x}}=-\alpha \psi \omega\left(S_{L}-S_{F}\right)
$$

Provided that $\hat{Q}=1$ for $\hat{x}=0,(37)$ is easily solved for $\hat{Q}$ :

$$
\hat{Q}=1-\alpha \psi \omega\left(S_{L}-S_{F}\right) \hat{x}
$$

By virtue of (16), this is also a solution for the dimensionless mud discharge $\hat{Q}_{m}$. The sand discharge $\hat{Q}_{s}$ is then obtained from (28):

$$
\hat{Q}_{s}=\left[1-\alpha \omega\left(S_{L}-S_{F}\right)(1-n) \hat{x}\right]^{1 / 1-n}
$$

[46] Relation (38) expresses the condition that the total discharge $\hat{Q}$ decreases linearly with the downstream distance, suggesting that the rate of flow overspill over the channel levees remains constant throughout the channel length. By comparison, the sand discharge reduces more rapidly in the upstream reaches, as prescribed by the power law relation (39). Notice that whereas by virtue of (35) the sand discharge peters out at the downstream end of the channel, where it delivers the exact amount of bed material required for the channel progradation, the total flow discharge and mud discharge do not reach zero at $\hat{x}=1$. Instead, (38) implies $\hat{Q}_{L}=\hat{Q}_{m L}=1-\alpha \psi \omega\left(S_{L}-S_{F}\right)$.

[47] In addition, the solution for $\hat{B}$ is obtained from (22):

$$
\hat{B}=\left[1-\alpha \omega\left(S_{L}-S_{F}\right)(1-n) \hat{x}\right]^{\frac{n}{1-n}}
$$

Solutions for $\hat{U}$ and $\hat{H}$ are obtained as

$$
\begin{aligned}
& \hat{U}=\hat{Q}_{s}^{\frac{1-n}{5}} \\
& \hat{H}=\frac{\hat{Q}}{\hat{B} \hat{U}}
\end{aligned}
$$

The solution for the slope is obtained from (18):

$$
\frac{1}{\hat{S}}=\frac{\varphi \hat{Q}_{s}+(1-\varphi) \hat{Q}_{m}}{\hat{B} \hat{U}^{3}}
$$

In order to close the above problem, it is necessary to find the effective diffusivity $\omega$ as a function of the other prescribed parameters. This is done by imposing the remaining boundary condition, namely a known slope value at the 
(a)

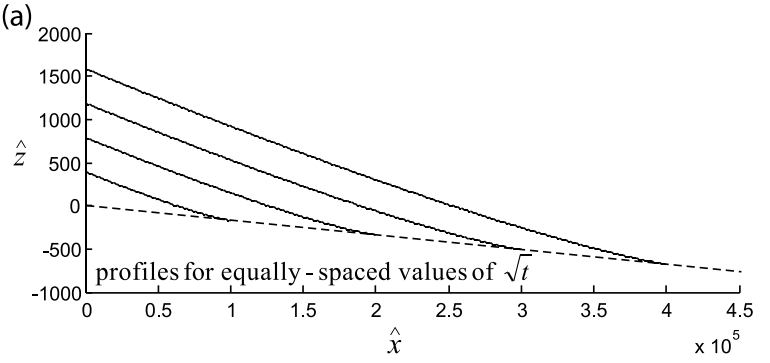

(b)

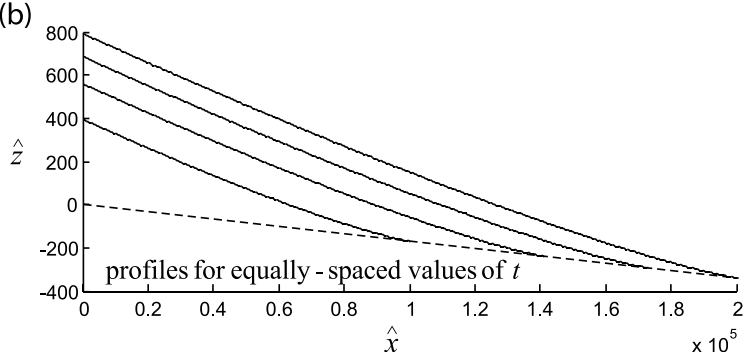

Figure 6. Self-similar evolution of the channel long profile (solid lines) as it aggrades and progrades on the surrounding fan (dashed line): (a) profiles at equidistant intervals of channel length $L\left(t^{\prime}\right)=\sqrt{2 \omega t^{\prime}}$; and (b) profiles at equidistant intervals of time $t^{\prime}$. The value of $n$ used in the calculation was 0.4 .

distal end of the channel where it connects to the yet unchannelized surrounding fan, i.e., $\hat{S}=\hat{S}_{L}=S_{L} / S_{0}$ when $\hat{x}=1$. This condition is substituted into (43) which may be solved for $\omega$. The analytical expression being cumbersome, the value of $\omega$ is here obtained numerically using a simple iterative root-finding scheme.

[48] The actual bed profile is then simply obtained by integration of (43), e.g., starting from a known reference level at the downstream end of the channel. A set of such self-similar bed profiles is presented in Figure 6 . They were obtained for flow conditions typical of the Amazon submarine channel, as will be discussed further in section 5. Figure $6 \mathrm{a}$ shows profiles corresponding to equally spaced values of the channel length $L\left(t^{\prime}\right)$, which by virtue of the similarity argument is related to the square root of time by (34). Profiles at equidistant pseudotime intervals are plotted in Figure $6 \mathrm{~b}$. As the channel lengthens by prograding onto the surrounding fan, the deposits spread over a longer distance and the global aggradation rate of the system declines.

\section{Comparison With Data From the Amazon Submarine Channel}

[49] The self-similar analytical solution described by (38)-(43) is analyzed here in the context of data for the Amazon channel of the Amazon Submarine Fan. Data pertaining to this channel have been digitized from Pirmez and Imran [2003]. It should be borne in mind that the channel has gone through several major avulsions during its evolution, which have likely constrained the morphological characteristics of the modern channel, especially in terms of levee height and channel relief. The quasi-equilibrium aggradation/progradation of the present model is assumed to hold only for long periods of time between avulsions.

\subsection{Model Setup}

[50] The Amazon Submarine Canyon-Fan system is dormant at the present high sea stand. Representative flow conditions appropriate to the last low stand, when the fan was likely active, must therefore be inferred.

[51] The simulated reach has a length of $370 \mathrm{~km}$ and extends from $x_{0}=70 \mathrm{~km}$ to $x_{L}=440 \mathrm{~km}$ as measured from the shelf edge, covering most of the leveed channel region where the proposed theory for the evolving long profile is expected to hold. The upstream end of the reach $\left(x_{0}=\right.$ $70 \mathrm{~km}$ ) coincides with the approximate canyon/fan transition, where values for the channel slope $S_{0}$ and width $B_{0}$ are imposed as boundary conditions to the model. These values are evaluated from the profiles of the present-day Amazon channel [Pirmez and Imran, 2003] at $x_{0}=70 \mathrm{~km}$, i.e., $S_{0}=$ 0.0068 and $B_{0}=4000 \mathrm{~m}$. The downstream end of the reach $\left(x_{L}=440 \mathrm{~km}\right)$ coincides with the location of the Brown channel avulsion, which is the latest major channel avulsion of the Amazon channel system [Pirmez and Imran, 2003]. The modern channel in the lower fan downstream of this point is characterized by a relatively constant slope, more frequent avulsions (paleochannels labeled $1 \mathrm{~A}$ to $1 \mathrm{~F}$ in Figure 1 [Hiscott et al., 1997]) and a lower degree of channelization; it is therefore excluded from consideration for the present model. Imposed values for the channel slope $S_{L}$ at the downstream end of the simulated reach, $x_{L}=$ $440 \mathrm{~km}$, as well as for the slope $S_{F}$ of the distal unchannelized fan, $x_{F}>600 \mathrm{~km}$, are again evaluated from the Amazon channel profiles of Pirmez and Imran [2003], i.e., $S_{L}=0.0028$ and $S_{F}=0.0017$.

[52] A major model parameter that must be prescribed is the relative sand/mud ratio of the inflowing turbidity currents at the canyon-fan transition. Pirmez et al. [2000] present several lines of evidence suggesting that turbidity currents that formed the Amazon channel had a supply sediment load which is about $10 \%$ sand and $90 \%$ mud; we adopt the value $\varphi=0.1$ hereafter. Mean flow concentration of mud is taken to be $c_{m}=1 \%$, a value proposed by Pirmez and Imran [2003] which is also in accordance with values derived from laboratory experiments of subcritical flows [Sequeiros et al., 2010a, 2010b]. We assume typical values for the porosity of the sandy channel deposits, $\lambda_{s}=0.4$, and muddy levee deposits, $\lambda_{m}=0.6$. A representative grain size for the sand fraction is taken to be $D=200 \mu \mathrm{m}$ based on core data at drill site ODP 934 which lies in the channel axis upstream of the Brown avulsion site [Pirmez, 1994]. Impacts of downstream fining and long-term compaction on the variation of the porosity of the deposits are neglected at this stage. The excess density of the sediment relative to water is taken to be $R=1.65$.

[53] Effective levee width is taken to be constant throughout the channel and equal to $B_{L}=32 \mathrm{~km}$. This is 8 times the width of the initial channel width $B_{0}$, a ratio which is deemed reasonable and in line with collected crosssectional seismic profiles (e.g., Figure 2).

[54] As already mentioned previously, turbidity currents entering the leveed channel system are presumed to be subcritical. We postulate a subcritical Froude number $F r_{d 0}=$ 0.5 at the entrance of the Amazon channel.

[55] The exponent $n$ used in the closure relation for width (equation (12)) is taken to be $n=0.4$, as proposed earlier. In 

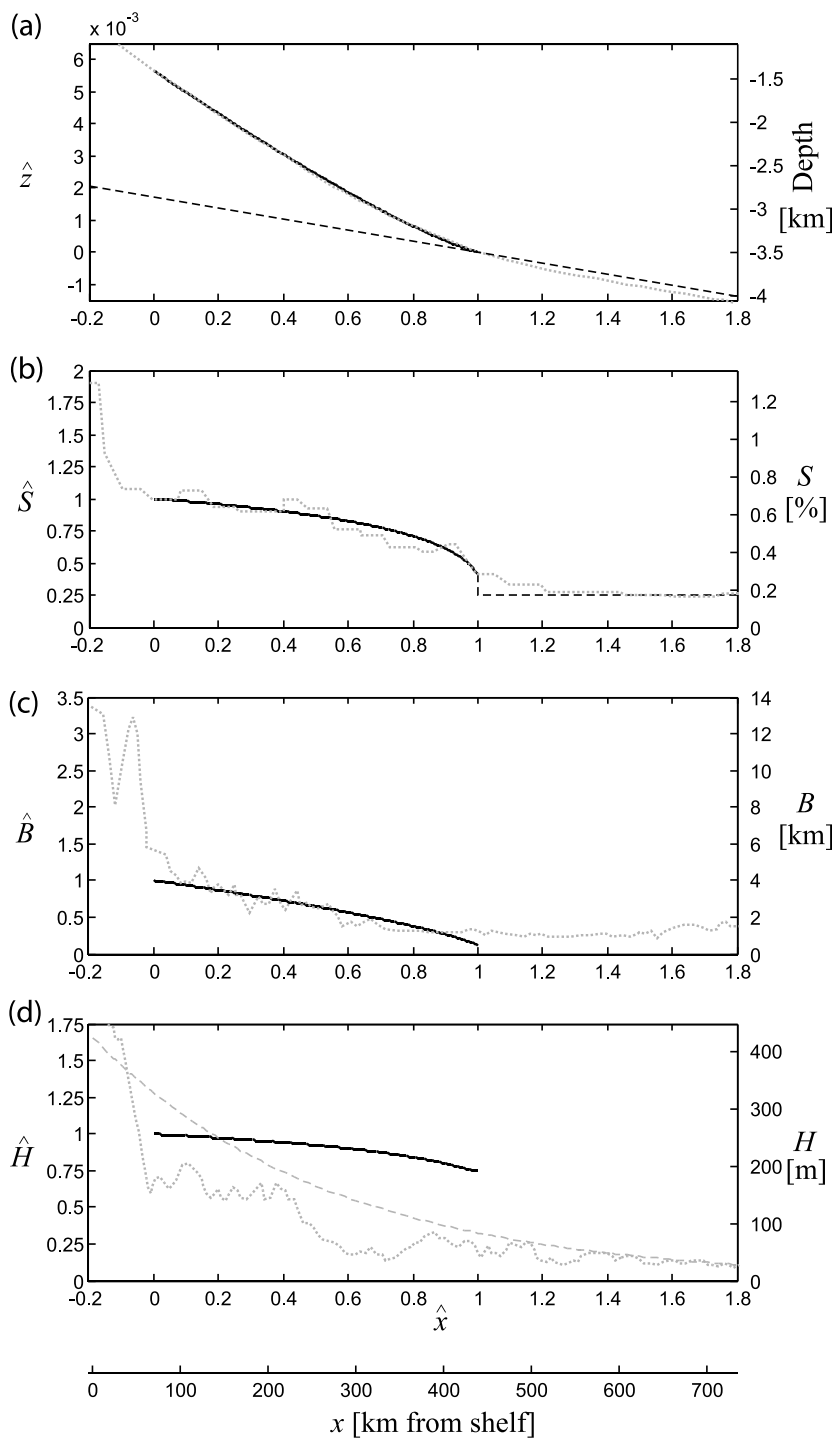

Figure 7. Comparison of model predictions (black curves) with actual data (gray dotted curves) of the Amazon submarine channel, for several meaningful morphological variables: (a) channel long profile, with the modeled surrounding fan plotted as the dashed black segment; (b) channel slope; (c) channel bankfull width; (d) channel relief, with the dashed gray curve representing the age-corrected exponential fit proposed by Pirmez and Imran [2003]. All scales are presented in dimensionless similarity variables on the left axis, as well as dimensional metric variables on the right axis. On the horizontal axis, actual downstream distance from the shelf edge is plotted in addition to dimensionless distance $\hat{x}$, with model results spanning over $\hat{x}=0$ to 1 . The more upstream reaches correspond to the incised canyon, and the more downstream reaches correspond to the modern, poorly channelized lower channel below the Brown paleoavulsion site.

so far as there appears to be no objective way at the present time to determine this parameter empirically or theoretically, it was here used as the single tuning parameter to fit the data.
[56] A summary of the input parameters is thus as follows: $x_{0}=70 \mathrm{~km} ; S_{0}=0.0068 ; B_{0}=4000 \mathrm{~m} ; x_{L}=440 \mathrm{~km} ; S_{L}=$ $0.0028 ; S_{F}=0.0017 ; \varphi=0.1 ; \lambda_{s}=0.4 ; \lambda_{m}=0.6 ; R=1.65$; $B_{L}=32 \mathrm{~km} ; F r_{d 0}=0.5$; and $n=0.4$. The values $x_{0}$ and $x_{L}$ imply a reach length $L$ of $370 \mathrm{~km}$.

\subsection{Model Predictions}

[57] With reasonable model parameters prescribed as above, the magnitude of channel-forming flows can then be inferred from the governing equations evaluated at the upstream end of the channel. Equation (11) yields a constant friction coefficient $C f=S_{0} / F r_{d 0}^{2}=0.027$. Combination with (4), (5) and (7) then allows, after some algebra, calculating the total inflow discharge, $Q_{0}=1.22 \times 10^{6} \mathrm{~m}^{3} / \mathrm{s}$. Given $c_{m}=$ $1 \%$ and $\varphi=0.1$, the delivered sand concentration in the inflow is $c_{s 0}=0.11 \%$. With a sediment density of about $2650 \mathrm{~kg} / \mathrm{m}^{3}(R=1.65)$, the delivered mud and sand discharges are respectively $Q_{m 0}=3210^{6} \mathrm{~kg} / \mathrm{s}$ and $Q_{s 0}=3.6 \times$ $10^{6} \mathrm{~kg} / \mathrm{s}$. The inflow velocity is $U_{0}=2.39 \mathrm{~m} / \mathrm{s}$, and the initial flow thickness is $H_{0}=255 \mathrm{~m}$.

[58] These values are in the range of proposed values obtained from the paleoreconstruction of Pirmez and Imran [2003], giving confidence that the estimated parameters imposed upstream $\left(F r_{d 0}, \varphi, \ldots\right)$ may not be too far from actual representative values for channel-forming flow conditions.

[59] The scaling factor of the self-similar solution, $\omega$, is obtained from the imposition of the conservation of sand at the downstream edge $x_{L}$ of the prograding channel according to (36). A closed form explicit analytical relation for $\omega$ as derived from (43) evaluated at $\hat{x}=1$ being unattainable, the scaling factor is instead obtained implicitly with a simple iterative scheme, yielding in this case $\omega=800 \mathrm{~m}^{2} / \mathrm{s}$.

[60] The above value of $\omega$, along with (34), (35) and the channel length $L=370 \mathrm{~km}$ given in section 5.1, allows the computation of progradation and aggradation rates $\partial L / \partial t^{\prime}$ and $\partial z / \partial t^{\prime}$ of $2.16 \times 10^{-3} \mathrm{~m} / \mathrm{s}$ and $2.38 \times 10^{-6} \mathrm{~m} / \mathrm{s}$, respectively. These values are expressed in pseudotime $t^{\prime}$; they can be converted into real time according to the relation $t^{\prime}=I t$ only upon the assumption of an intermittency $I$. Appropriate data for this purpose are given by Normark et al. [1997, pp. 641-642]. They note that "the rate of downfan advance of the levee termination zone of an active channel-levee system [on the Amazon Submarine Fan] therefore can be as much as $20 \mathrm{~m} / \mathrm{yr}$ ". Adopting $20 \mathrm{~m} / \mathrm{yr}$ as the value for $\partial L / \partial t$ and using the value for $\partial L / \partial t^{\prime}$ in the above paragraph, an intermittency $I$ can be estimated as $2.93 \times 10^{-4}$, corresponding to channel-forming flows being sustained for $2.57 \mathrm{~h} / \mathrm{yr}$.

[61] The predicted ratio of the progradation rate to the aggradation rate is found from (35) to be $\left(\partial L / \partial t^{\prime}\right) /\left(\partial z / \partial t^{\prime}\right)=$ $1 /\left(S_{L}-S_{F}\right)=909$. This compares with the following statement by Normark et al. [1997, pp. 641-642]: "This progradation rate [of $20 \mathrm{~m} / \mathrm{yr}$ ] is about three orders of magnitude greater than the average sediment aggradation rate on levee crests...."

\subsection{Comparison With Long Profiles for the Amazon Channel}

[62] Simulated long profiles of meaningful morphological variables are compared with actual data for the Amazon channel in Figures 7 and 8. In Figure 7, profiles are drawn in 

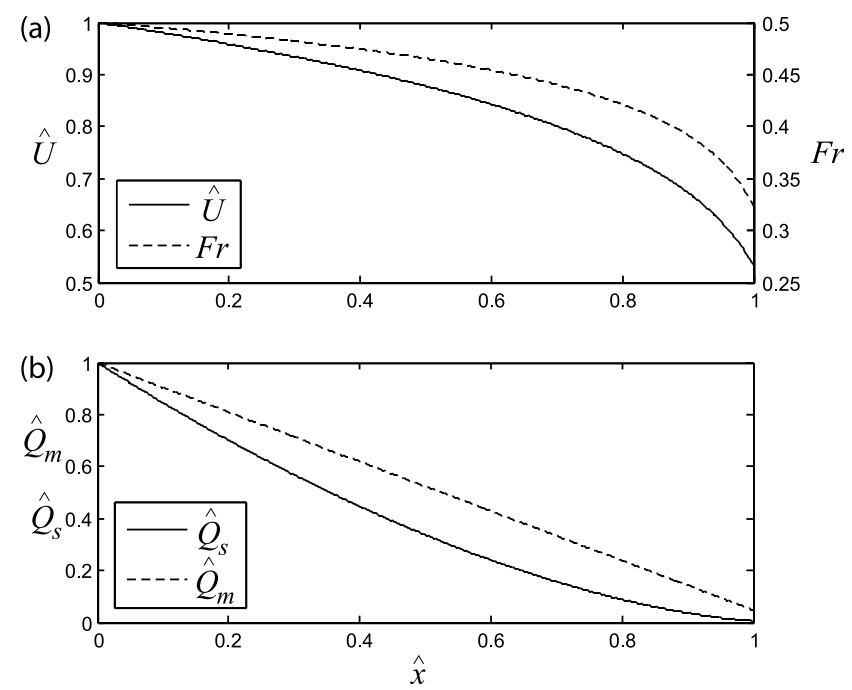

Figure 8. Model predictions for the long profiles of sediment discharges and flow characteristics associated with channel-forming turbidity currents in the Amazon submarine channel: (a) cross-section-averaged current velocity and densimetric Froude number; and (b) sand and mud discharges of sediment suspended in the flow. All plots are presented in dimensionless similarity variables.

terms of dimensionless similarity variables $\hat{z}, \hat{S}, \hat{B}$ and $\hat{H}$ on the left axis, and corresponding dimensional metric variables on the right axis. On the horizontal axis, actual downstream distance, in kilometers from the shelf edge, is indicated for reference in additional to dimensionless downstream distance $\hat{x}$. Figure 7 a compares simulated and observed long profiles of the channel bed. Although the simulation focuses on the actively channelized portion of the fan system, data pertaining to the Amazon Canyon upstream, and to the less well channelized portion of the lower fan downstream, are plotted for reference. Over the considered reach the agreement between modeled and measured values is fairly good. Figure $7 \mathrm{~b}$ compares the evolution of channel slopes. The model successfully predicts the gradual reduction in channel slope over the considered reach. The slope is seen to follow an upward convex profile, indicating that the channel slope declines more rapidly as it nears its downstream end. Over the considered reach at least, the data tend to support this behavior. At the downstream end of it, the model assumes a sudden drop in slope as the channel connects to the unchannelized fan, as illustrated by the dotted lines in Figure $7 \mathrm{~b}$. The observations suggest a more gradual reduction as, presumably, the flow progressively loses track of its channel and spreads onto the distal fan.

[63] Figure 7c shows that the proper trend is obtained for the downstream reduction in channel width. Figure $7 \mathrm{~d}$ illustrates the predicted downstream variation in flow thickness. Also shown is a line corresponding to the observed channel depth. In addition Pirmez and Imran [2003] have estimated an age-corrected profile of levee thickness, and fitted an exponential profile to it which is plotted as a dashed gray curve in Figure 7d. As required by the model, the predicted flow thickness is larger than the channel depth. As opposed to the modeling results of Pirmez and Imran [2003], the present model predicts a downstream reduction in flow thickness, a trend that corresponds to the data. Having said that, the predicted flow thickness drops off less rapidly downdip than channel depth. Whether or not this result is physically correct is difficult to ascertain at this point.

[64] The downstream change in modeled current velocity, shown in Figure 8a, shows the anticipated downdip slow down of the current. In terms of the densimetric Froude number, Figure $8 \mathrm{a}$ shows that the currents indeed become more and more subcritical as they travel down channel, dropping from $F r_{d 0}=0.5$ upstream to $F r_{d \mathrm{~L}} \approx 0.35$ downstream.

[65] Figure $8 \mathrm{~b}$ shows the downstream reduction in sand and mud discharge. As is expected, the current loses sand at a faster rate than mud in the proximal reaches. However, at the terminal portion of the channel, $\hat{x}=1$, the flow has run out of neither mud nor sand. The remaining sediment content acts as building material for the channel to extend downdip.

\section{Model Sensitivity and Limitations}

[66] Elongated submarine leveed channel systems are found in many subsea sedimentary environments around the globe. The proposed theory aims at reaching a better understanding of what governs the long-term evolution of these channels. It is based on the hypothesis that these submarine channels may reach a quasi-equilibrium state of evolution, just like subaerial river channels do in a constrained hydrological and sedimentological environment. Knowledge about river systems has been accumulated over a much longer period and broader research community than submarine systems. In this sense the present theory represents a first attempt of conceptualization that may open the path for more refined descriptions.

[67] When analyzed in the context of data for the Amazon submarine channel, the model yields encouraging predictions. Its application to other submarine channels, lying on fans of a different scale, slope, or delivered sand to mud ratio, should rely on a good understanding of its behavior and parameter sensitivity. While a lengthy exploration of the full parameter space is beyond the scope of the present paper, much of the physical behavior of the system is essentially embedded in three dimensionless parameters: (1) the effective diffusivity $\omega$ governing the rate of channel progradation, (2) the sand to mud ratio, expressed here in terms of $\varphi$, the percentage of sand in the delivered sediment, and (3) the ratio of levee width to channel width, here evaluated at the entrance of the channel reach, $B_{L} / B_{0}$.

[68] Figure 9 presents a synthetic plot of $\omega=f\left(\varphi, B_{L} / B_{0}\right)$, with all other variables fixed as estimated above for the Amazon channel. Slope values $S_{F}$ and $S_{L}$ being kept constant when preparing Figure 9, so is the ratio of channel aggradation to channel progradation by virtue of (35); with the help of (36), additional color maps in Figure 9 are therefore presented directly in terms of channel aggradation and progradation. As they depend on the particular set of parameters used for comparison with the Amazon channel, these rates are not universal and are plotted here only for reference. Note also that these rates are expressed in pseudotime $t^{\prime}$.

[69] Figure 9 highlights several important characteristics of the model behavior. First, the hatched region in the upper right of Figure 9 represents a domain where the model has 

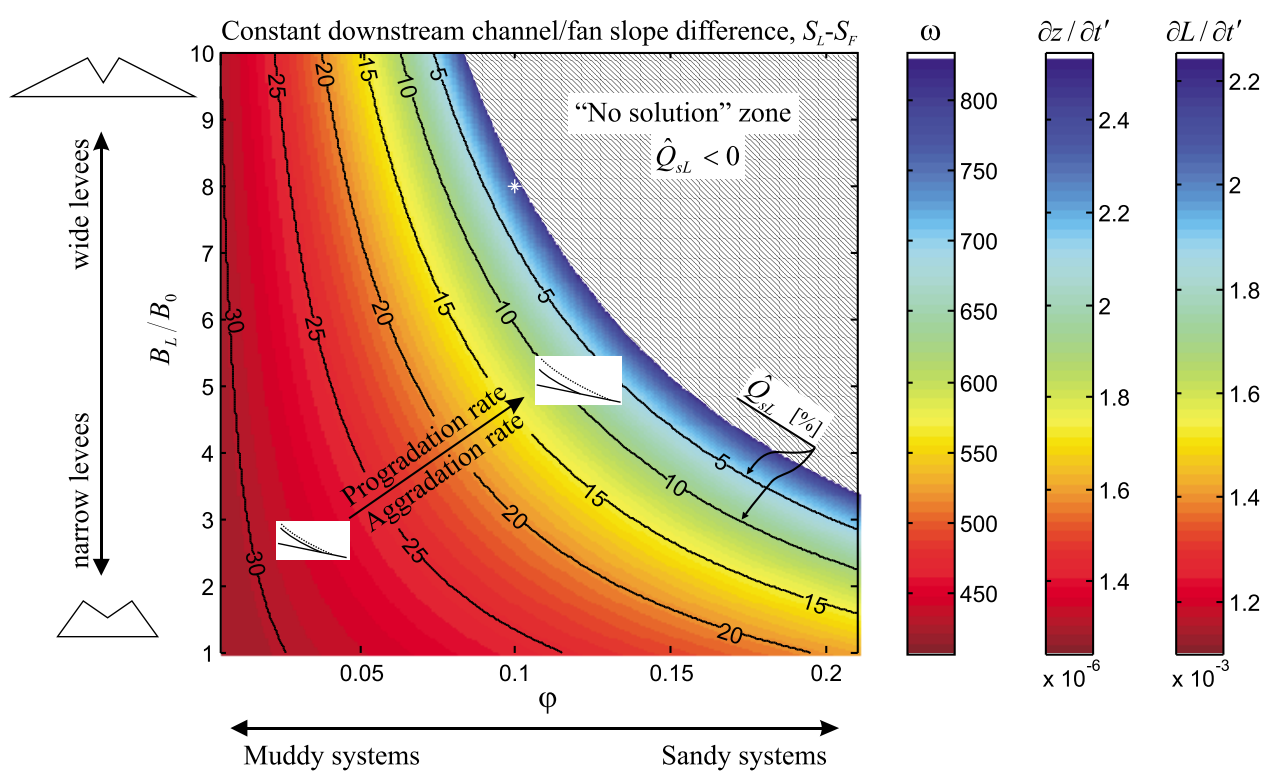

Figure 9. Sensitivity analysis of model behavior. Plot of effective diffusivity $\omega=f\left(\varphi, B_{L} / B_{0}\right)$ for a constant downstream channel/fan slope difference, $S_{L}-S_{F}$, with other variables fixed as estimated for the Amazon channel in section 5. The white star represents the actual set of model parameters used in the comparison with the Amazon channel presented in section 5.

no admissible solution: adequate balance between sand and mud deposition along the channel length is impossible to achieve, and the sand peters out before reaching the end of the channel, inhibiting progradation of the channel tip. This imposes an upper limit on the effective diffusivity, and hence the channel aggradation/progradation. Second, isocontours of effective diffusivity are concave upward, following the trend of the limit of admissible domain. For a given channel/levee width ratio, tracing a horizontal line on Figure 9, channel systems with a larger sand/mud ratio will evolve (aggrade/ prograde) more rapidly. For a given sand/mud ratio, tracing a vertical line on Figure 9, narrower channels with wider levees will evolve more rapidly. Overall, Figure 9 suggests that sand-rich leveed channel systems will tend to produce narrower levees and aggrade/prograde at a faster rate.

[70] Figure 10 similarly presents a synthetic plot of aggradation rate $\partial z / \partial t^{\prime}=f\left(\varphi, B_{L} / B_{0}\right)$ for a fixed diffusivity (here taken equal to $\omega=800 \mathrm{~m}^{2} / \mathrm{s}$ as in section 5) and progradation rate. Given (36), $\partial z / \partial t^{\prime}$ is now a proxy for the downstream channel/fan slope difference, $S_{L}-S_{F}$, which is given as the first color bar. Figure 10 suggests that relatively sand-rich channels will tend to adopt steeper slope profiles, and will aggrade more rapidly, than relatively mud-rich systems.

[71] In Figures 9 and 10, the white star represents the actual set of model parameters used in the comparison with the Amazon channel presented in section 5. It is anticipated that the application of the model to other leveed channels, including smaller-scale slope channels, will provide additional points to add on the plots, and will enrich the discussion about typical slope profiles of leveed submarine channels around the globe. Such an exploration of other channel systems, however, is left for further work by us or the community, and will critically depend on the collection and usability of appropriate data.

[72] The present model is based on reasonable but necessarily simplified assumptions about the channel geometry, flow mechanics, and mode of construction, all based on the current knowledge of submarine channel systems and turbidity currents. The predicted self-similar evolution mimics important anticipated features of actual submarine channels, as the down-channel reduction of slope, width and flow thickness, the consistent construction of muddy levees and coarser channel fills, and the concurrent channel aggradation and progradation.

[73] Yet several important limitations may be identified. The first, and possibly most important limitation, lies in the postulated mode of channel aggradation linked to the bimodal behavior of transported sediment, mud being assumed to behave as a passive contaminant and to deposit solely and entirely on the levees to build them up, and sand being assumed to be transported at rates dependent on local bed shear stresses and to deposit solely on the channel bed. Besides representing a crude idealization of the variable granulometry of sediment transported by turbidity currents, this likely introduces a bias toward sand-rich submarine sedimentary basins. Babonneau et al. [2002, 2005] compare the morphological characteristics of sand-rich versus mudrich systems, the Amazon system forming an analog for the former, and the Congo forming an analog for the second. It is clear that other constitutive assumptions will have to be invoked for sand-starved channel systems, and the present theory is not expected to adequately model e.g., the Congo channel, which is markedly incised within the surrounding fan for a large part of its length, and while it emplaces muddy levees, shows no signs of significant sandy deposits as channel fills, the limited sand content being bypassed through the channel system and directly transferred to the distal lobes region. It is anticipated that, as opposed to the present, purely and continuously aggrading self-similar channel profiles, a first theory for the long profiles of channels like the Congo might possibly be based on an 


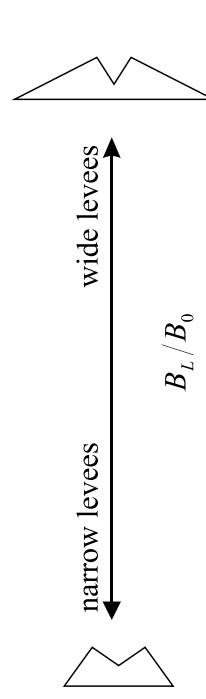

Constant diffusivity $\omega$ (hence constant progradation rate)

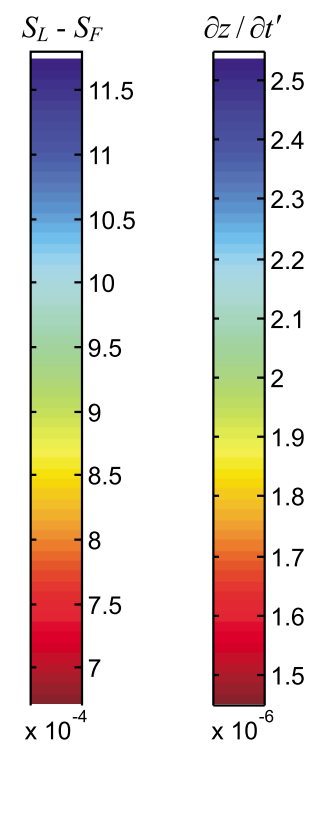

Figure 10. Sensitivity analysis of model behavior. Plot of aggradation rate $\partial z / \partial t^{\prime}=f\left(\varphi, B_{L} / B_{0}\right)$ for a constant diffusivity $\left(\omega=800 \mathrm{~m}^{2} / \mathrm{s}\right)$ and progradation rate $\left(\partial L / \partial t^{\prime}=2.16 \times 10^{-3} \mathrm{~m} / \mathrm{s}\right)$, and other variables fixed as estimated for the Amazon channel in section 5. The white star represents the actual set of model parameters used in the comparison with the Amazon channel presented in section 5.

"at-grade" hypothesis, similar to the one adopted by Gerber et al. [2009] to model steep submarine canyons.

[74] In addition, while the simplified set of assumptions that were adopted allowed to deliver an analytical solution for the channel evolution, several other limitations may be briefly stated as follows.

[75] 1. The model does not account for channel meandering. It does not allow model meandering, nor does it account for its effects on the relative budgets of channel versus levee sediment volumes. The importance of meandering is underlined by e.g., Imran et al. [1999], Peakall et al. [2000], Straub et al. [2008] and Sylvester et al. [2011].

[76] 2. The model does not account for the effects of antecedent channel avulsions, its impacts on the levee thickness, the formation and migration of knickpoints in the profile and the reincision of antecedent channel fills.

[77] 3. The model does not account for downstream fining of sediment, and especially the coarser fraction of sand, which impacts the transport capacity of sediment by a given flow. This effect is known to be important in large sand bed rivers [Wright and Parker, 2005a, 2005b]. As opposed to a channel emplaced by currents transporting a uniform grain size, channels transporting graded sediment mixtures may have a steeper decline in channel slope, with coarser sediment being deposited at a steeper slope in the proximal reaches, and finer sediment being transferred to distal reaches where they deposit at a milder slope. The effect for the Amazon channel is likely modest, with channel axis grain size data fining by a factor of 3 over a distance of $320 \mathrm{~km}$, from $450 \mu \mathrm{m}$ at drill site ODP 934 to $150 \mu \mathrm{m}$ at site ODP 945 [Pirmez and Imran, 2003].

[78] 4. The model accounts neither for the effect of entrainment of ambient seawater into the current, which would thicken the current and increase the amount of levee overflow, though the effect is presumably small for confined subcritical turbidity currents, nor for the vertical stratification of mud, which would tend to reduce the amount of mud lost per unit of overflow [e.g., Straub et al., 2008]. These two effects will tend to counterbalance each other as far as the lateral deposition of mud on the levees is concerned.

[79] 5. The model assumes a constant lateral extent of the levees throughout the channel length, despite the fact that the data shows levee width gradually reduces down channel. However, the model predicts a gradual steepening of the levee in time, a factor that has been suggested to gradually lead the channel to incipient avulsion.

[80] 6 . The model relies on a tuning parameter $n$ in order to characterize the downstream variation in channel width. At present there is no obvious way to overcome this shortcoming.

[81] Figure 6 illustrates a channel/levee system that is becoming ever more perched about the surrounding fan surface as it aggrades. This is indeed the morphology that is observed on the Amazon Submarine Fan (e.g., Figure 2b). An increasing elevation difference between levee top and the surrounding fan corresponding to increasing velocity of the overspilling part of the turbidity current as it flows down the levee. Sufficient flow velocity can lead to levee scour, and thus incipient avulsion [e.g., Fildani et al., 2006]. The present can be used as a tool to estimate conditions for incipient avulsion.

\section{Conclusions}

[82] A predictive model has been proposed that describes the quasi-equilibrium morphodynamics of aggrading, leveebounded channels on submarine fans created by turbidity 
currents. Sand is deposited in the channel and mud is deposited on the levees. The quasi-equilibrium state is characterized by a channel and levees that aggrade in concert at a constant spatial rate, and aggrade/prograde at a rate that decreases in time. It is intended to approximate a state prevailing during an extended period between channel avulsions.

[83] The morphodynamics of the problem are described in terms of an equation of flow momentum balance, a sand transport equation, mass balance for water, sand and mud, a shock condition describing channel/levee progradation at the downstream end, and an empirical closure for channel width which must be tuned against data. The problem defines a complex nonlinear diffusion, but can be solved rather simply under an appropriate similarity assumption. According to this assumption, both the progradation rate and aggradation rate decline as time to the half power as sand deposits over an ever longer channel.

[84] The model is tested against data for the Amazon channel of the Amazon Submarine Fan. Once an exponent $n$ in the width relation is tuned, the model adequately predicts the downdip variation of channel slope, width and other parameters. The model can be used to predict not only channel evolution between periods of avulsion, but also the progression toward incipient avulsion as the elevation difference between levee top and the surrounding fan increases in time.

[85] The present model is designed for submarine fan systems that have enough supply of both sand and mud to allow the formation of channels that are perched above the surrounding fan. This is the case for the Amazon Submarine Fan, as well as many others. The channels on the Congo Submarine Fan, on the other hand, are commonly incised into the fan over most of their length. This appears to be due to a starvation of sand supply as compared to mud.

[86] Acknowledgments. Funding for this work was provided by ExxonMobil Exploration Co. Discussions with C. Pirmez, L. Pratson, and D. Mohrig are gratefully acknowledged. The first author acknowledges support of the Fonds pour la Recherche Scientifique, Belgium.

\section{References}

Babonneau, N., B. Savoye, M. Cremer, and B. Klein (2002), Morphology and architecture of the present canyon and channel system of the Zaire deep-sea fan, Mar. Pet. Geol., 19, 445-467, doi:10.1016/S0264-8172 (02)00009-0.

Babonneau, N., B. Savoye, L. Droz, A. Morash, and M. Bez (2005), Large modern deep-sea fans: The Amazon channel versus the Zaire/Congo channel, paper 90039 presented at AAPG Annual Meeting, Calgary, Alberta, 19-22 June.

Capart, H., M. Bellal, and D. L. Young (2007), Self-similar evolution of semi-infinite alluvial channels with moving boundaries, J. Sediment. Res., 77, 13-22, doi:10.2110/jsr.2007.009.

Clark, J. D., and K. T. Pickering (1996), Submarine Channels Process and Architecture, 229 pp., Vallis, London.

Cui, Y., and G. Parker (1997), A quasi-normal simulation of aggradation and downstream fining with shock fitting, Int. J. Sediment Res., 12(2), 68-82.

Cui, Y., and G. Parker (1998), The arrested gravel front: Stable gravel-sand transitions in rivers. Part 2: General numerical solution, J. Hydraul. Res., 36(2), 159-182, doi:10.1080/00221689809498631.

Damuth, J. E., and R. D. Flood (1985), Amazon Fan, Atlantic Ocean, in Submarine Fans and Related Turbidite Systems, edited by A. H. Bouma, N. E. Barnes, and W. R. Normark, pp. 97-106, Springer, New York.

Damuth, J. E., R. D. Flood, R. O. Kowsmann, R. H. Belderson, and M. A. Gorini (1988), Anatomy and growth pattern of Amazon Deep-Sea Fan as revealed by long-range side-scan sonar (GLORIA) and high-resolution seismic studies, AAPG Bull., 72(8), 885-911.

Droz, L., F. Rigaut, P. Cochonat, and R. Tofani (1996), Morphology and recent evolution of the Zaire turbidite system (Gulf of Guinea), Geol. Soc. Am. Bull., 108(3)253269doi:10.1130/0016-7606(1996)108<0253: MAREOT $>2.3 . \mathrm{CO} ; 2$.

Ellison, T. H., and J. S. Turner (1959), Turbulent entrainment in stratified flows, J. Fluid Mech., 6, 423-448, doi:10.1017/S0022112059000738.

Elverhøi, A., D. Issler, F. V. De Blasio, T. Ilstad, C. B. Harbitz, and P. Gauer (2005), Emerging insights into the dynamics of submarine debris flows, Nat. Hazards Earth Syst. Sci., 5(5), 633-648, doi:10.5194/nhess-5-633-2005.

Engelund, F., and E. Hansen (1967), A Monograph on Sediment Transport, Technisk Forlag, Copenhagen, Denmark.

Fildani, A., W. R. Normark, S. Kostic, and G. Parker (2006), Channel formation by flow stripping: Large-scale scour features along the Monterey East Channel and their relation to sediment waves, Sedimentology, 53, 1265-1287, doi:10.1111/j.1365-3091.2006.00812.x.

Flood, R. D., D. J. W. Piper, and A. Klaus, and the Shipboard Scientific Party (1995), Proceedings of the Ocean Drilling Program, Initial Reports, vol. 155, Ocean Drill. Program, College Station, Tex.

Garcia, M., and G. Parker (1989), Experiments on hydraulic jumps in turbidity currents near a canyon-fan transition, Science, 245, 393-396, doi:10.1126/science.245.4916.393.

Gerber, T. P., D. Amblas, M. A. Wolinsky, L. F. Pratson, and M. Canals (2009), A model for the long-profile shape of submarine canyons, J. Geophys. Res., 114, F03002, doi:10.1029/2008JF001190.

Hay, A. E. (1987a), Turbidity currents and submarine channel formation in Rupert Inlet, British Columbia: 1. Surge observations, J. Geophys. Res., 92, 2875-2881, doi:10.1029/JC092iC03p02875.

Hay, A. E. (1987b), Turbidity currents and submarine channel formation in Rupert Inlet, British Columbia: 2. The roles of continuous and surge type flow, J. Geophys. Res., 92, 2883-2900, doi:10.1029/JC092iC03p02883.

Hiscott, R. N., F. R. Hall, and C. Pirmez (1997), Turbidity current overspill from Amazon Channel: Texture of the silt/sand load, paleoflow from anisotropy of magnetic susceptibility, and implications for flow processes, Proc. Ocean Drill. Program Sci. Results, 155, 53-78.

Imran, J., G. Parker, and N. Katopodes (1998), A numerical model of channel inception on submarine fans, J. Geophys. Res., 103(C1), 1219-1238, doi:10.1029/97JC01721.

Imran, J., G. Parker, and C. Pirmez (1999), A nonlinear model of flow in submarine and subaerial meandering channels, J. Fluid Mech., 400, 295-331, doi:10.1017/S0022112099006515.

Kenyon, N. H., A. Amir, and A. Cramp (1995), Geometry of the younger sediment bodies on the Indus Fan, in Atlas of Deep Water Environments: Architectural Style in Turbidite Systems, edited by K. T. Pickering et al., pp. 89-93, Chapman and Hill, London.

Kneller, B. (2003), The influence of flow parameters on turbidite slope channel architecture, Mar. Pet. Geol., 20, 901-910, doi:10.1016/j.marpetgeo. 2003.03.001.

Kolla, V., and F. Coumes (1987), Morphology, internal structure, seismic stratigraphy and sedimentation of Indus Fan, AAPG Bull., 71, 650-677.

Kostic, S., O. E. Sequeiros, B. Spinewine, and G. Parker (2010), Cyclic steps: A phenomenon of supercritical shallow flow from the high mountains to the bottom of the ocean, J. Hydroenviron. Res., 3, 167-172, doi:10.1016/j.jher.2009.10.002.

Lai, S. Y. J., and H. Capart (2009), Reservoir infill by hyperpycnal deltas over bedrock, Geophys. Res. Lett., 36, L08402, doi:10.1029/2008GL037139.

Leopold, L. B. (1994), A View of the River, 298 pp., Harvard Univ. Press, Cambridge, Mass.

Masson, D. G., C. B. Harbitz, R. B. Wynn, G. Pedersen, and F. Lovholt (2006), Submarine landslides: Processes, triggers and hazard prediction, Philos. Trans. R. Soc. A, 364, 2009-2039, doi:10.1098/rsta.2006.1810.

Meiburg, E., and B. Kneller (2010), Turbidity Currents and Their Deposits, Annu. Rev. Fluid Mech., 42, 135-156, doi:10.1146/annurev-fluid-121108145618.

Normark, W. R., J. E. Damuth, and the Leg 155 Sedimentology Group (1997), Sedimentary facies and associated depositional elements of the Amazon Fan, Proc. Ocean Drill. Program Sci. Results, 155, 611-651. doi:10.2973/odp.proc.sr.155.247. (Available at http://www-odp.tamu. edu/publications/155_SR/155TOC.HTM\#40.)

Paola, C. (1989), A simple basin-filling model for coarse-grained alluvial systems, in Quantitative Stratigraphy, edited by T. A. Cross, pp. 363-374, Prentice Hall, Englewood Cliffs, N. J.

Paola, C., P. L. Heller, and C. L. Angevine (1992), The large-scale dynamics of grain-size variation in alluvial basins. I: Theory, Basin Res., 4, 73-90. Parker, G. (1991a), Selective sorting and abrasion of river gravel. I: Theory, J. Hydraul. Eng., 117(2), 131-149, doi:10.1061/(ASCE)0733-9429(1991) 117:2(131). 
Parker, G. (1991b), Selective sorting and abrasion of river gravel, II: Applications, J. Hydraul. Eng., 117(2), 150-171, doi:10.1061/(ASCE)07339429(1991)117:2(150).

Parker, G., and Y. Cui (1998), The arrested gravel front: Stable gravel-sand transitions in rivers. Part 1: Simplified analytical solution, J. Hydraul. Res., 36(1), 75-100, doi:10.1080/00221689809498379.

Parker, G., Y. Fukushima, and H. Pantin (1986), Self-accelerating turbidity currents, J. Fluid Mech., 171, 145-181, doi:10.1017/S0022112086001404.

Parker, G., C. Paola, K. X. Whipple, D. Mohrig, C. M. Toro-Escobar, M. Halverson, and T. W. Skoglund (1998a), Alluvial fans formed by channelized fluvial and sheet flow, II: Application, J. Hydraul. Eng., 124(10), 996-1004, doi:10.1061/(ASCE)0733-9429(1998)124:10(996).

Parker, G., C. Paola, K. X. Whipple, and D. Mohrig (1998b), Alluvial fans formed by channelized fluvial and sheet flow. I: Theory, J. Hydraul. Eng., 124(10), 985-995, doi:10.1061/(ASCE)0733-9429(1998)124:10(985).

Parker, G., P. R. Wilcock, C. Paola, W. E. Dietrich, and J. Pitlick (2007), Physical basis for quasi-universal relations describing bankfull hydraulic geometry of single-thread gravel bed rivers, J. Geophys. Res., 112, F04005, doi:10.1029/2006JF000549.

Parker, G., T. Muto, Y. Akamatsu, W. E. Dietrich, and J. Lauer (2008), Unravelling the conundrum of river response to rising sea-level from laboratory to field. Part II. The Fly Strickland River system, Papua New Guinea, Sedimentology, 55, 1657-1686, doi:10.1111/j.1365-3091.2008.00962.x.

Peakall, J., B. McCaffrey, and B. Kneller (2000), A process model for the evolution, morphology, and architecture of sinuous submarine channels, J. Sediment. Res., 70, 434-448, doi:10.1306/2DC4091C-0E47-11D7$8643000102 \mathrm{C} 1865 \mathrm{D}$

Pirmez, C. (1994), Growth of a submarine meandering channel-levee system on the Amazon Fan, Ph.D. thesis, Columbia Univ., New York.

Pirmez, C., and R. D. Flood (1995), Morphology and structure of the Amazon Fan Channel, Proc. Ocean Drill. Program, Initial Rep., 155, 23-45.

Pirmez, C., and J. Imran (2003), Reconstruction of turbidity currents in Amazon Channel, Mar. Pet. Geol., 20, 823-849, doi:10.1016/j.marpetgeo. 2003.03.005.

Pirmez, C., R. T. Beaubouef, S. J. Friedmann, and D. C. Mohrig (2000), Equilibrium profile and base level in submarine channels: Examples from late Pleistocene systems and implications for the architecture of deepwater reservoirs, in Deepwater Reservoirs of the World [CD-ROM], edited by P. Weimer et al., pp. 782-805, GCSSEPM Found., Houston, Tex.

Reading, H. G., and M. Richards (1994), Turbidite systems in deep-water basin margins classified by grain size and feeder systems, AAPG Bull. 78(5), 792-822.

Sequeiros, O. E., B. Spinewine, M. H. Garcia, R. T. Beaubouef, T. Sun, and G. Parker (2009), Experiments on wedge-shaped deep sea sedimentary deposits in minibasins and/or on channel levees emplaced by turbidity currents. Part I. Documentation of the flow, J. Sediment. Res., 79, 593-607, doi:10.2110/jsr.2009.064.

Sequeiros, O. E., B. Spinewine, R. T. Beaubouef, T. Sun, M. H. Garcia, and G. Parker (2010a), Bedload transport and bed resistance associated with density and turbidity currents, Sedimentology, 57, 1463-1490, doi:10.1111/j.1365-3091.2010.01152.x.

Sequeiros, O. E., B. Spinewine, R. T. Beaubouef, T. Sun, M. H. Garcia, and G. Parker (2010b), Characteristics of velocity and excess density pro- files of saline underflows and turbidity currents flowing over a mobile bed, J. Hydrol. Eng., 136, 412-433, doi:10.1061/(ASCE)HY.19437900.0000200 .

Simpson, J. E. (1987), Gravity Currents: In the Environment and the Laboratory, 244 pp., John Wiley, New York.

Sinha, S. K., and G. Parker (1996), Causes of concavity in longitudinal profiles of rivers, Water Resour. Res., 32(5), 1417-1428, doi:10.1029/ 95WR03819.

Snow, R. S., and R. L. Slingerland (1987), Mathematical modeling of graded river profiles, J. Geol., 95, 15-33, doi:10.1086/629104.

Spinewine, B., O. E. Sequeiros, M. H. Garcia, R. T. Beaubouef, T. Sun, B. Savoye, and G. Parker (2009), Experiments on wedge-shaped deep sea sedimentary deposits in minibasins and/or on channel levees emplaced by turbidity currents. Part II. Morphodynamic evolution of the wedge and of the associated bedforms, J. Sediment. Res., 79, 608-628, doi:10.2110/ jsr.2009.065.

Spinewine, B., O. E. Sequeiros, T. Sun, and G. Parker (2010), Experiments and analytical solution for a prograding wedge-shaped deposit produced by turbidity currents transporting gravel mixtures, in River, Coastal and Estuarine Morphodynamics: RCEM 2009, edited by C. A. Vionnet et al., pp. 249-255, Taylor and Francis, London.

Straub, K. M., D. Mohrig, B. McElroy, J. Buttles, and C. Pirmez (2008), Interactions between turbidity currents and topography in aggrading sinuous channels: A laboratory study, Mem. Geol. Soc. Am., 120, 368-385, doi:10.1130/B25983.1.

Sylvester, Z., C. Pirmez, and A. Cantelli (2011), A model of submarine channel-levee evolution based on channel trajectories: Implications for stratigraphic architecture, Mar. Pet. Geol., 28, 716-727, doi:10.1016/j. marpetgeo.2010.05.012.

Twichell, D. C., N. H. Kenyon, L. M. Parsons, and B. A. McGregor (1991), Depositional patterns of the Mississippi Fan surface: Evidence from GLORIA II and high-resolution seismic profiles, in Seismic Facies And Sedimentary Processes of Submarine Fans and Turbidite Systems, edited by P. Weimar and M. H. Link, pp. 349-364, Springer, New York.

Voller, V. R., J. B. Swenson, and C. Paola (2004), An analytical solution for a Stefan problem with variable latent heat, Int. J. Heat Mass Transfer, 47(24), 5387-5390, doi:10.1016/j.ijheatmasstransfer.2004.07.007.

Wright, S., and G. Parker (2005a), Modeling downstream fining in sandbed rivers. I: Formulation, J. Hydraul. Res., 43(6), 612-619.

Wright, S., and G. Parker (2005b), Modeling downstream fining in sandbed rivers, J. Hydraul. Res., 43(6), 620-630.

N. Babonneau, Laboratoire de Géosciences Marines, CNRS, Université de Brest, F-29200 Brest, France.

G. Parker, Department of Civil and Environmental Engineering, University of Illinois Urbana-Champaign, Room 2527-C, Urbana, IL 61801, USA.

B. Spinewine, Institute of Mechanics, Materials and Civil Engineering, Université catholique de Louvain, Place du Levant 1, B-1348 Louvainla-Neuve, Belgium. (benoit.spinewine@uclouvain.be)

T. Sun, ExxonMobil Exploration Co., PO Box 2189, Houston, TX 77252-2189, USA. 